03

\title{
Исследование теплового излучения элементов подгруппы титана с учетом фазовых переходов
}

\author{
() Д.В. Косенков, В.В. Сагадеев, В.А. Аляев \\ Казанский национальный исследовательский технологический университет, \\ 420015 Казань, Республика Татарстан, Россия \\ e-mail: Dmi-kosenkov@yandex.ru
}

Поступило в Редакцию 18 января 2021 г.

В окончательной редакции 2 февраля 2021 г.

Принято к публикации 25 февраля 2021 г.

\begin{abstract}
Проведено экспериментальное измерение излучательной способности элементов четвертой группы (титан, цирконий, олово и свинец) периодической системы Д.И. Менделеева абсолютным радиационным способом в атмосфере инертного газа или в вакууме. Измерения проведены на экспериментальном стенде собственной конструкции и разработки. Исследованы температурные зависимости нормальной интегральной степени черноты в твердой и жидкой фазах состояния веществ. Температуры ограничивались упругостью паров нагреваемых веществ до предельного состояния кипения элементов.
\end{abstract}

Ключевые слова: экспериментальные исследования, степень черноты, фазовый переход, периодическая система.

DOI: $10.21883 / J T F .2021 .07 .50949 .9-21$

Знания радиационных характеристик, применяемых конструкционных материалов, позволяют проводить теплотехнические расчеты лучистого теплообмена при проектировании теплонагруженного оборудования и установок.

К настоящему времени экспериментальное определение теплового излучения металлов проведено для ограниченного ряда элементов, в связи с большой трудностью исследования и различными ограничениями в проведении эксперимента.

В настоящей работе приведены экспериментально полученные температурные зависимости степеней черноты чистых металлов IV группы периодической системы от температуры. Авторами были исследованы степени черноты таких веществ, как титан, олово, цирконий и свинец в зависимости от температуры.

На основании обзора существующих методов экспериментального определения степени черноты веществ был выбран абсолютный радиационный метод исследования. Спроектирован и создан экспериментальный стенд для измерения нормальных интегральных степеней черноты твердых и жидких металлов, сплавов и элементов периодической системы. Экспериментальная установка размещена в научно-исследовательской лаборатории на базе кафедры „Вакуумная техника электрофизических установок“ Казанского национального исследовательского технологического университета.

Экспериментальный стенд позволяет проводить исследование веществ и металлов как в вакууме, так и в атмосфере инертного газа до предельных температур кипения вещества и работоспособности резистивного нагревателя танталовой ленты.

Достоверность полученных результатов обеспечивается применением аттестованных измерительных средств с оценкой их погрешности и устойчивой воспроизводимостью результатов опытов при проведении экспериментальных исследований.

По существующей методике ГОСТ Р 8.736-2011 авторами произведена оценка погрешности эксперимента, состоящей из систематической и случайной ошибок. Максимальная относительная погрешность по оценке авторов составляла $\pm 2 \%$. С учетом градуировки применяемой вольфрам-рениевой термопары в температурном интервале от 1500 до $3000 \mathrm{~K}$, максимальная погрешность опыта была оценена от 5 до $8 \%$ в зависимости от температуры. С увеличением температуры эксперимента погрешность опыта уменьшается.

Все исследованные материалы имели химическую чистоту с содержанием основного элемента не хуже $99.999 \%$.

В настоящей работе многократно тестировалось воспроизведение показаний степеней черноты с результатами по предыдущим измерениям, в качестве образцовых значений использовалась излучательная способность титана и олова [1-5].

По результатам измерений был сделан однозначный вывод, что температурные зависимости степеней черноты титана и олова, полученные авторами (рис. 1,2), имеют согласие с литературными данными в пределах погрешности эксперимента.

Исследование степени черноты титана проводилось авторами по существующей методике [5].

Титан, как элемент этой группы, показывает уверенный рост излучательной способности от температуры с характерными пиками фазовых переходов как в твердой фазе, так и при температуре плавления. 


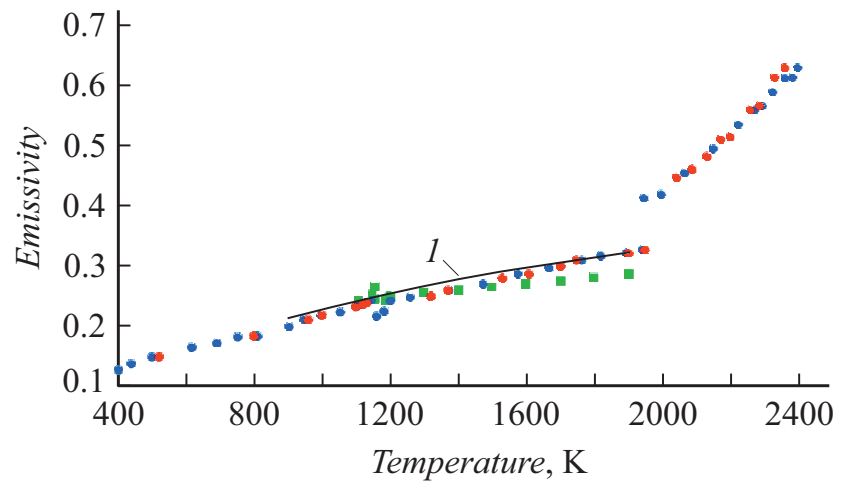

Рис. 1. Температурная зависимость степени черноты титана: $1-[1] ;$ квадраты - [3]; • (голубого цвета в online версии)[4]; • (красного цвета в online версии) - измерения авторов настоящей работы.

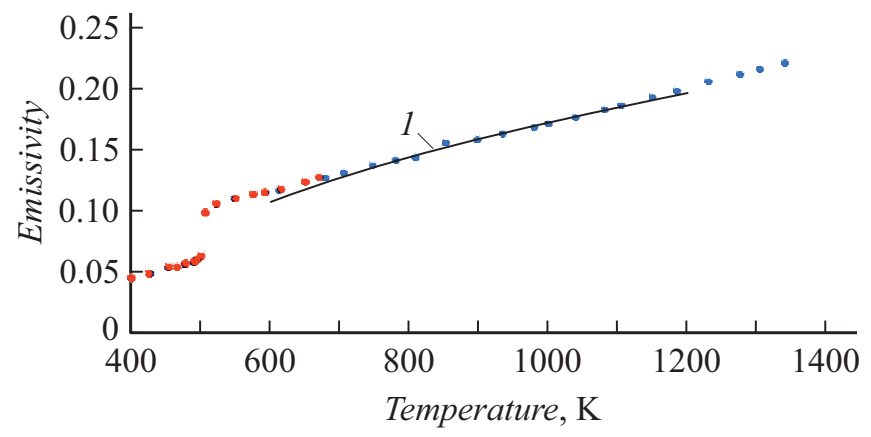

Рис. 2. Температурная зависимость степени черноты олова: линия $1-[10] ; \bullet$ (голубого цвета в online версии) - [4]; - (красного цвета в online версии) - измерения авторов настоящей работы.

Рост степени черноты титана составляет порядка $27 \%$ от твердой фазы и полностью зависит от характера разупорядочивания кристаллической решетки этого металла.

Олово (рис. 2) показывает монотонный уверенный рост излучательной способности от температуры. Фазовый переход твердое тело-жидкость дает положительный скачок роста степени черноты $65 \%$.

При исследовании циркония авторами была впервые получена температурная зависимость излучения циркония на существующем экспериментальном стенде (рис. 3). Литературные значения степени черноты циркония хорошо сопоставляются только лишь в твердой фазе. Данные работы [6], по мнению авторов настоящей работы, являются завышенными, что может быть связано с химической чистотой исследуемого металла.

Поведение излучательной способности циркония хорошо согласуется с разрывом ковалентных связей металла при плавлении и описывается конфигурацией атомов кристаллической решетки.

Авторами зафиксирован скачок изменения степени черноты циркония на $20 \%$ при фазовом переходе твердое тело-жидкость.
Прослеживается аналогичная последовательность положительного изменения степени черноты, характерная для металлов IV группы периодической системы. Увеличение металлизации свойств элемента также соответствует его расположению в периодической таблице Д.И. Менделеева.

Степени черноты кристаллического свинца были измерены авторами в температурном диапазоне от $400 \mathrm{~K}$ (рис. 4), что является продолжением роста степени черноты свинца, показанного в работе [7]. Так как авторами не была получена оптически гладкая поверхность образца, полученные значения степени черноты, согласно теории $[8,9]$, могут являться завышенными.

Рост степени черноты твердой фазы и бросок излучения при фазовом переходе твердое тело-жидкость был оценен авторами величиной $80 \%$. Уверенный рост степени черноты в жидкой фазе согласуется с результатами работы [10].

По результатам приведенных экспериментальных исследований вышеперечисленных металлов было подтверждено наличие постоянного скачка интегральной нормальной степени черноты при плавлении металлов и дальнейшего роста степени черноты с увеличением температуры. Также сделан вывод, что величина скачка излучательной способности при фазовом переходе твердое

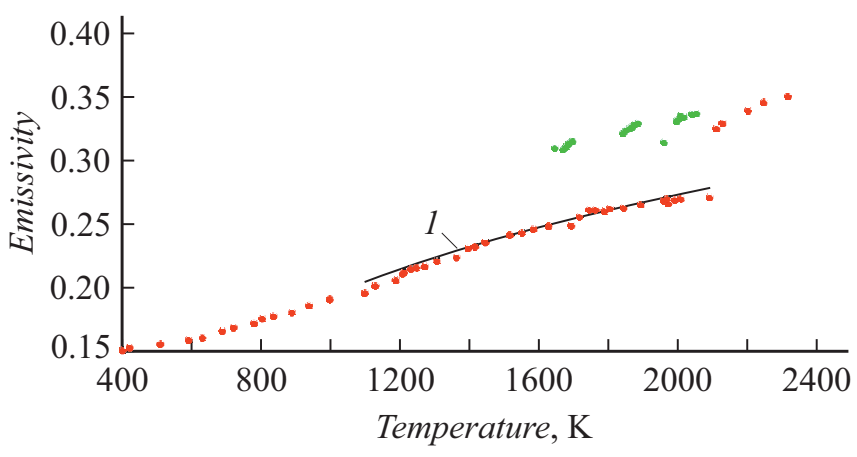

Рис. 3. Температурная зависимость степени черноты циркония: линия $1-[1]$; • (зеленого цвета в online версии) [6]; • (красного цвета в online версии) - измерения авторов настоящей работы.

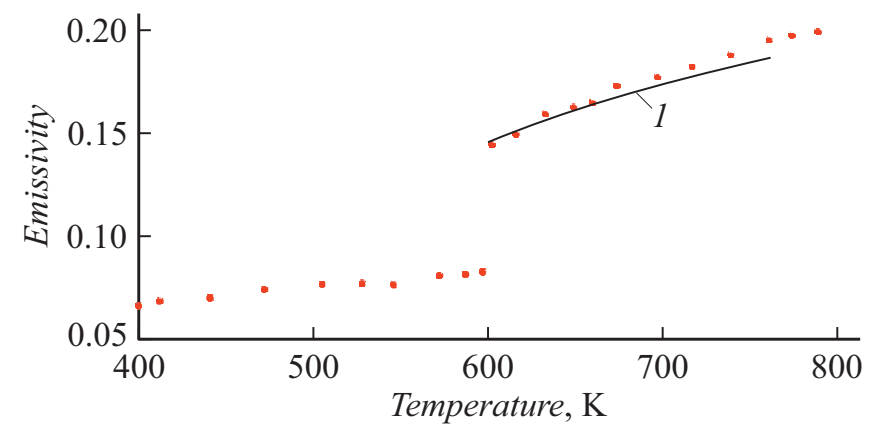

Рис. 4. Температурная зависимость степени черноты свинца: $1-[10] ;-($ красного цвета в online версии) - измерения авторов настоящей работы. 
тело-жидкость зависит от соответствующего положения элемента в периодической таблице Д.И. Менделеева.

Понимание природы плавления металлов свидетельствует о том, что она не может быть отождествлен лишь с мерой разупорядочивания кристаллической решетки в смысле изменения конфигурации расположения атомов и колебательного спектра металла.

\section{Конфликт интересов}

Авторы заявляют, что у них нет конфликта интересов.

\section{Список литературы}

[1] Излучательные свойства твердых металлов. Справочник. Под общ. ред. А.Е. Шейндлина. (Энергия, М., 1974)

[2] В.В. Сагадеев, В.А. Аляев. Излучательная способность жидких металлов и сплавов: монография (Изд-во КНИТУ, Казань, 2018)

[3] Б.А. Шур, В.Э. Пелецкий. Интегральная полусферическая излучательная способность титана в диапазоне температур 1100-1900 К. Рекомендованные справочные данные № 56-83.1983.

[4] К.Б. Панфилович, П.И. Бударин, В.В. Сагадеев, В.А. Глинкин. ИФЖ, 68, (2), 271 (1995).

[5] К.Б. Панфилович, В.В. Сагадеев, И.Л. Голубева. ТВТ, 42 (5), 718 (2004).

[6] A. Cezairliyan, F. Righini. J. Res. National Bureau Standards. A. Phys. Chem. 78 (4), 509 (1974).

[7] Л.А. Новицкий, Б.М. Степанов. Оптические свойства материалов при низких температурах (Машиностроение, М., 1980)

[8] R. Siegel, J.R. Howell. Thermal Radiation Heat Transfer (Taylor \& Francis, N. Y., 2002)

[9] А.Г. Блох, Ю.А. Журавлев, Л.Н. Рыжков. Теплообмен излучением: справочник (Энергоатомиздат, М., 1991)

[10] К.Б. Панфилович. Тепловое излучение и поверхностное натлжение жмидих металлов и сплавов: монография (Изд-во Казан. гос. тех. ун-та, Казань, 2009) 